\title{
Into the mind of a killer
}

\section{Brain imaging studies are starting to venture into the legal minefield of research into criminal psychopathy. Alison Abbott reports from one of the most controversial frontiers of neuroscience.}
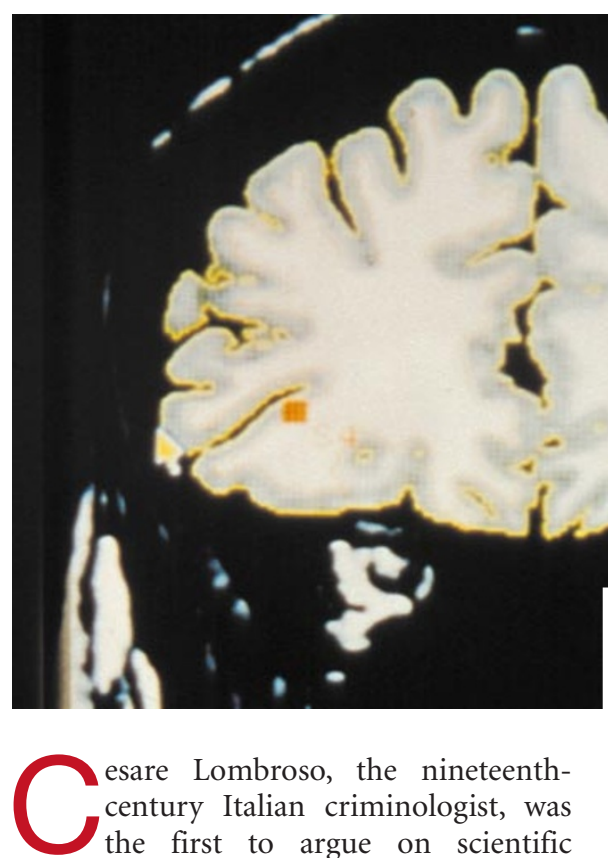

esare Lombroso, the nineteenthcentury Italian criminologist, was the first to argue on scientific grounds that criminals are born, not made. Drawing on emerging theories of evolution and genetics, and the contemporary fad for phrenology, he concluded that those with a 'criminal mind' could be identified by deformations of their skulls. It all seemed reasonable at the time. But the facts did not fit the theory, and Lombroso's research was later discredited.

Today, many psychiatrists accept that some people who fall foul of the criminal justice system suffer from a condition psychopathy - that is as much an illness as, for example, schizophrenia. Environmental factors may help to determine whether this 'illness' is expressed in the form of violent, criminal behaviour, but a growing number of experts argue that the underlying condition is biological. "More and more data are leading to the conclusion that psychopathy has a biological basis, and has many features of a disease," says Sabine Herpertz, a psychiatrist at the RWTH-Aachen University in Germany.

Several researchers are now using the latest brain imaging techniques in an attempt to find out what is different about the brains of psychopaths. They hope that these studies will lead to a fundamental biological understanding of psychopathy, and perhaps even to drug treatments for the condition.

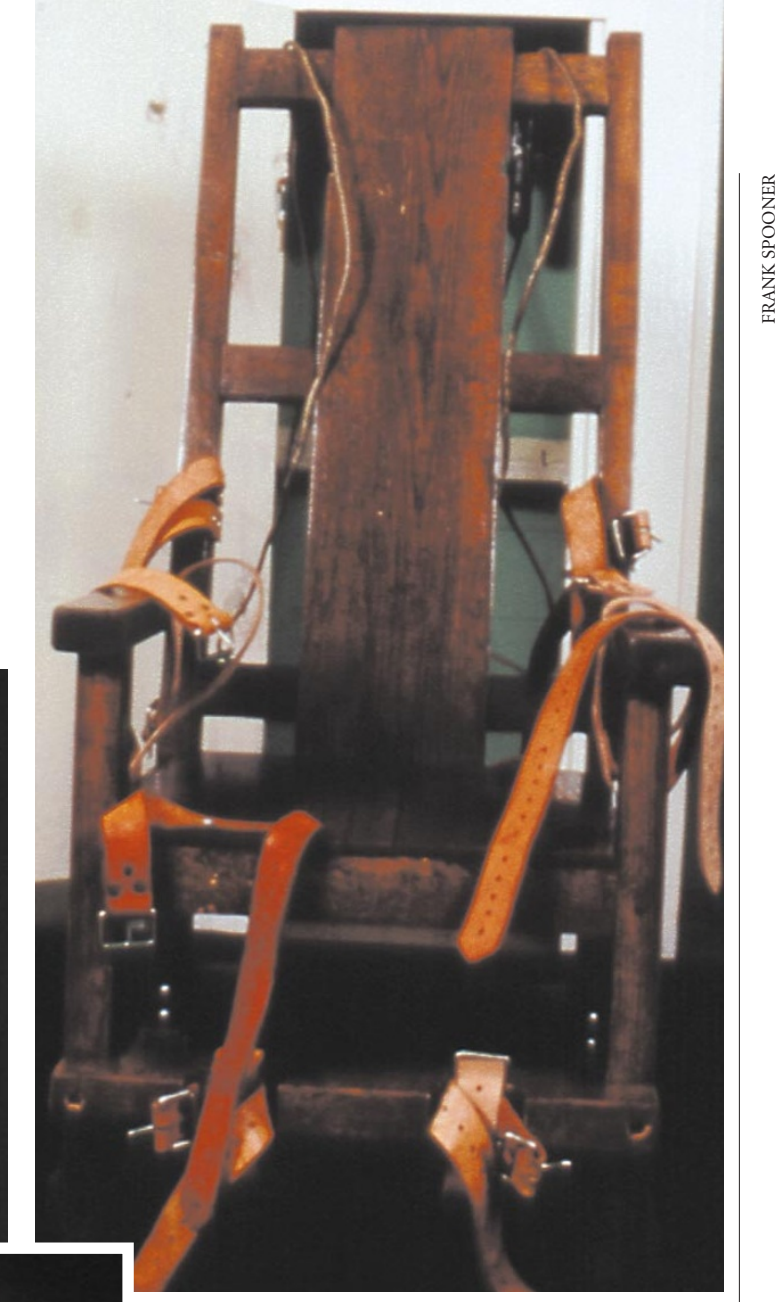

Life or death: will brain research save psychopaths from the chair, or send them to it?

unconcerned by the negative consequences of their actions. When they kill, the crimes are usually well planned and committed for personal gain. But engage in conversation with a psychopath, and he or she might seem perfectly normal.

\section{Inhuman behaviour}

Psychopaths form part of a wider group diagnosed as suffering from antisocial personality disorder (APD). They can be identified using a test developed by Robert Hare, a psychologist at the University of British Colombia in Vancouver, ${ }^{1,2}$. Diagnoses of APD are based primarily on patients' behavioural histories, but Hare's revised psychopath check-list (PCL-R) uses psychiatrists' assessments of the emotional deficits that underlie psychopathy.

An estimated three-quarters of prison populations fulfil the criteria for APD, and a quarter or more may exceed a PCL-R score of 30 , the cut-off for true psychopathy ${ }^{3,4}$. PCL-R scores also seem to predict the likelihood of reoffence ${ }^{5}$. Around four times as many psychopaths commit violence on release from jail as those simply diagnosed as having APD; and for psychopaths, the risk of reoffending is independent of the environment into which they return. Moreover, the higher the PCL-R score, the more likely they are to reoffend.

Being able to identify psychopaths using a check-list does not explain the condition's 
biological basis. But long before the advent of brain-scanning techniques, psychologists were identifying physiological correlates of psychopathy that appeared to be linked to the underlying emotional deficit. Hare conducted many pioneering experiments in the 1960s. In some, for example, he exposed subjects to an unpleasantly loud noise after either a countdown or a visual stimulus. Over repeated trials, normal people became anxious as the countdown began or the visual stimulus was flashed up, and they began to sweat, increasing their skin conductivity. But psychopaths consistently showed low skinconductivity responses ${ }^{6}$.

More recently, research has been extended to other physiological parameters. Everyone blinks when startled, and normally this response becomes more intense if they are placed in a threatening environment which can be simulated in the lab by showing subjects a picture of an angry face. But in psychopaths, the startle response remains unchanged under these circumstances .

Psychopaths also respond differently to words that normally evoke an emotional response, such as 'kill', 'maim' or 'joy'. In tests in which people have to separate real words from nonsense words, normal volunteers process these emotionally charged words more slowly than neutral words, such as 'table' and 'butter'. But psychopaths process both categories of word at the same speed ${ }^{8}$.

\section{Image consultants}

The brain imaging techniques of positron emission tomography (PET) and magnetic resonance imaging (MRI) provide the opportunity to investigate psychopathy further. They might allow researchers to discover whether psychopaths' physiological and emotional deficits can be pinned down to specific differences in the anatomy or activation of the brain.

Among researchers who are starting to explore this area, there are two main theories of psychopathy. One, championed by Adrian Raine of the University of Southern California in Los Angeles and supported by the work of Antonio Damasio of the University of Iowa, gives a starring role to a brain region called the orbitofrontal cortex (see diagram, right). This is part of an area of the brain, known as the prefrontal cortex, involved in conscious decision-making. Damasio has shown, for example, that patients who have suffered damage in this area early in life have severe social behavioural problems and can be very aggressive?

The other theory, promoted by James Blair of University College London, holds that the fundamental dysfunction lies within the amygdala, a small almond-shaped structure that plays a critical role in processing emotion and mediating fear. Recently, using PET scanning, Blair has shown that activation of the amygdala in normal volunteers is involved in responding to the sadness and

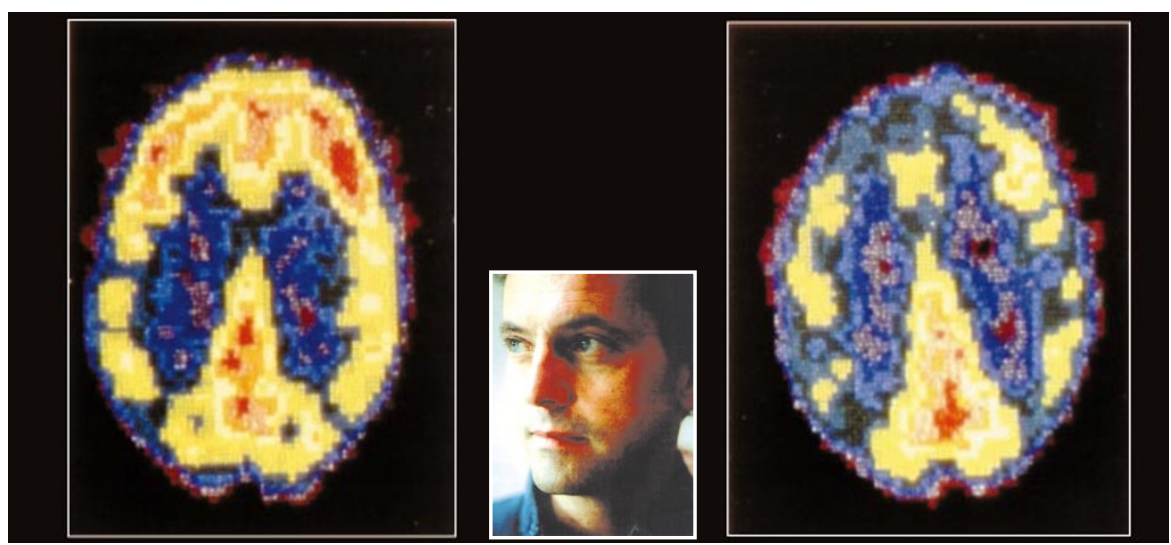

Mind games: Adrian Raine with PET scans of a normal brain (left) and that of a murderer. But, given the uncertainties about diagnosis, the significance of such work to psychopathy remains unclear.

anger of others ${ }^{10}$, and he hypothesizes that amygdala dysfunction could explain the lack of fear and empathy in psychopaths.

The two theories may not be mutually exclusive, Blair points out, as the orbitofrontal cortex, which does the 'thinking', and the amygdala, which does the 'feeling, are highly interconnected.

So far, evidence from neuroimaging studies is inconclusive. It is consistent with the theory that a deficit in emotional processing underlies psychopathy, as brain scans show a reduction in size, or changes in the activation of brain areas associated with emotional processing - including the prefrontal cortex, the amygdala, and other components of the limbic' system. But the findings do not promote one particular neurobiological theory.

One of the biggest problems is that many of the studies undertaken so far have used subjects who are not pure psychopaths. For example, Raine has used PET scans to compare the activity of the brains of murderers both those who killed in a fit of rage, termed 'affective' murderers, and 'predatory' killers — with normal volunteers ${ }^{11}$. He found anomalies in the scans of affective murderers, but not in those of predators. Some of the latter group may have been psychopaths, but none had been diagnosed using the PCL-R.

Last year, Raine's team published an MRI study of 21 men diagnosed as having APD, who admitted - under guarantee of confi-

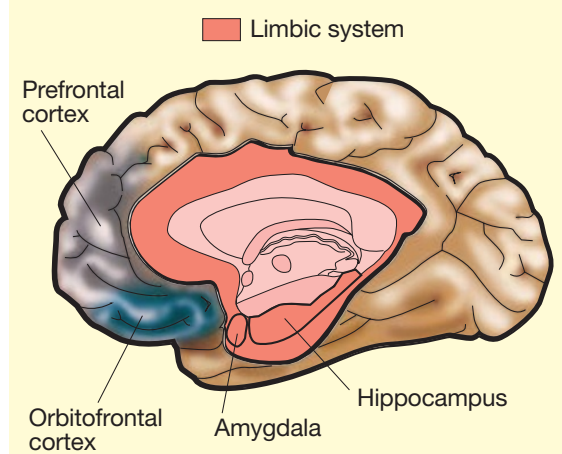

Danger areas: psychopathy has been associated with dysfunction in several parts of the brain. dentiality - to having committed violent crimes $^{12}$. Compared with normal volunteers, these men had shrunken prefrontal cortices - reduced in volume by up to $14 \%$. The results grabbed the headlines, but their significance for true psychopathy remains unclear. Again, the volunteers had not been rated using the PCL-R, and shrunken prefrontal cortices are also associated with substance abuse - so the finding could merely indicate an association between drug-taking and APD.

Another study, published earlier this year by Mikko Laasko and his colleagues at Kuopio University Hospital in Finland ${ }^{13}$, used MRI to look at the volume of the hippocampus, part of the limbic system, in 18 male alcoholics who averaged a score of 31.2 on the PCL-R scale. There was a strong correlation between the PCL-R score and hippocampal shrinkage, but the conclusions were confounded because of the subjects' alcoholism.

\section{Learned hostilities}

Studies attempting to apply functional MRI (fMRI) to psychopathy are still in their infancy, and only one has been published so far. By monitoring blood flow within the brain, fMRI can study the activation of different brain areas at high resolution during the performance of specific tasks. Last year, psychologist Frank Schneider of the University of Düsseldorf and his colleagues described fMRI experiments in which 12 individuals with APD who scored highly on the PCL-R check-list, and 12 normal controls, were alternately exposed to a face with an emotionally neutral expression and a nasty smell ${ }^{14}$. This is a standard 'aversive conditioning' procedure, in which the expression on the face is perceived as more hostile as the experiment proceeds.

Both groups showed aversive conditioning, but in the APD patients activity was increased in both the amygdala and the prefrontal cortex while making the emotional association between the smell and the face. Superficially, this seems to argue against theories that a lack of activation in these brain areas is linked to psychopathy. But Schneider 


\section{news feature}

- suggests that the findings could indicate that psychopaths, because of their deficit in emotional processing, have to make a much greater effort to learn the associations forged in aversive conditioning experiments. But Schneider's sample included several subjects with a PCL-R score of less than 30.

\section{Courting problems}

The difficulty in interpreting such studies is adding to the unease of scientists who fear that the researchers involved are in danger of repeating Lombroso's mistakes. Claudio Luzzatti, a neuropsychologist at the University of Milan-Bicocca, argues that in other areas fMRI has muddied the waters, as its findings are often inconsistent with neuropsychological approaches. In studies of patients with brain damage, areas shown to be crucial for word comprehension and reading do not light up when these tasks are tracked by fMRI; whereas other brain regions, which had never been considered crucial, do. "It's not always easy to work out what fMRI is showing us," says Luzzatti.

John Marshall, a neuropsychologist at the University of Oxford, is similarly unconvinced by the studies conducted so far. "Criminality does not seem to be the kind of thing that can be localized," he says. "I am extremely sceptical about what people are actually measuring."

Hare agrees that neuroimaging studies of psychopaths should be interpreted with great caution. He adds that progress is hampered by the paucity of information about what the brains of various individuals look like when they are processing emotional information. "What we need are a set of standard tests for all sorts of clinical populations and normals," Hare says.

Scientists who have served as expert witnesses are concerned about how data from neuroimaging studies of psychopaths might be used in court. Helen Mayberg, chair of neuropsychiatry at the Rotman Institute in Toronto, says that PET scans are already being

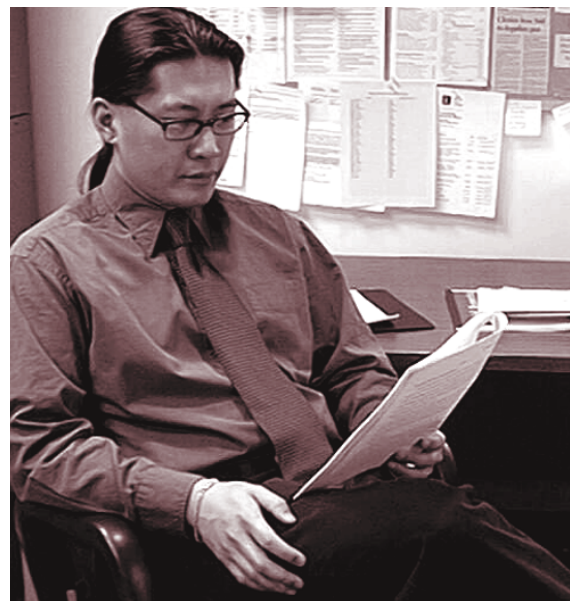

No way back: Michael Seto has seen behavioural therapy consistently fail in psychopaths. used in an unscientific way by US defence lawyers - not to address the issue of psychopathy, but in a general attempt to convince courts to accept pleas of diminished responsibility. "A prisoner with no clinical diagnosis is taken for a PET scan - in shackles and maybe with a death sentence hanging over him," she says. "This is then compared with that of a non-shackled healthy person, and used in court as evidence of his state of mind at the scene of a crime committed years earlier."

But proponents of neuroimaging research into psychopathy counter that such studies promise a more complete picture of psychopathy as a disease. In the long run, this could lead to changes in the law, allowing psychopaths to claim diminished responsibility and so routinely be sent to secure mental institutions rather than to prison. And as understanding of the neurobiological basis of psychopathy grows, newideas for therapy may emerge."The more we know about the biology of psychopathy, the clearer will be the path to the design of effective pharmacotherapy," argues Blair.

\section{Dark side of the brain}

Pharmacological approaches to treating psychotherapy would certainly be welcome. Behavioural therapy, in which psychopaths are put through programmes designed to help them change their behaviour patterns, has been spectacularly unsuccessful. For example, Michael Seto and Howard Barbaree of the University of Toronto followed the incidence of violent reoffending among 224 former prisoners who had undergone behavioural therapy before their release $\mathrm{e}^{15}$. Those with high PCL-R scores, apparently doing well in therapy, actually reoffended more often than those scoring lower for psychopathy, who seemed to respond less well to behavioural therapy. Seto says that this result could reflect the manipulative nature of some psychopaths: the more psychopathic, the better they may be at convincing psychologists of progress under therapy.

One fundamental problem for psychopathy research is that there has historically been scant funding. "This is really the study of the dark side of human nature, and it finds few benefactors," says Hare.

But in Britain, that may be about to change. Following widespread concern that the criminal justice and mental health systems are failing to deal effectively with dangerous psychopaths, the government is planning fundamental reform. Most controversially, it intends to reform the Mental Health Act to allow "dangerous people with severe personality disorder" to be detained in secure mental institutions even if they have been accused of no crime. Although these particular provisions have alarmed civil liberties campaigners, the raft of measures also includes a major initiative within the prison service to improve the handling of those with APD - including psychopaths.

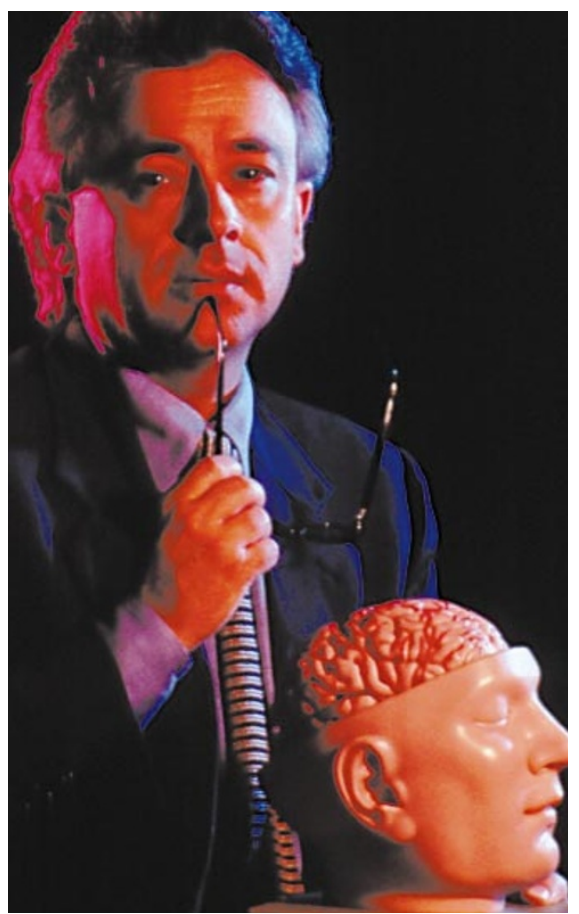

Thinking big: Antonio Damasio believes

neuroscientists should investigate psychopathy.

Significantly, this initiative includes an annual $\mathfrak{E} 1$ million (US\$1.5 million) research component, some of which may be used to support brain imaging and other neurobiological studies. One protocol under consideration, for instance, would follow the incidence of violent reoffence in released prisoners with high PCL-R scores and either high or low ratings on neurobiological indicators of emotional deficit.

Researchers who believe that neurobiological approaches offer the greatest potential for treating psychopathy hope that the British programme really will back the necessary research. "As it is clear that brain dysfunction can cause abnormal social behaviour, it is important for scientists to address the issue," says Damasio. "The human mind is complex and refined - but scientists should not be afraid to think big."

Alison Abbott is Nature's senior European correspondent

1. Hare, R. D. et al. Psychol. Assessment 2, 338-341 (1990).

2. Hare, R. D. Manual for the Hare Psychopathy Checklist-Revised (Multi Health Systems, Toronto, 1991).

Widiger, T. A. et al. J. Abnorm. Psychol. 105, 3-16 (1996).

4. Hobson, J. \& Shine, J. Br. J. Criminol. 38, 405-515 (1998).

5. Hemphill, J. F., Hare, R. D. \& Wong, S. Legal Criminol. Psychol. 3, 141-172 (1998).

6. Hare, R. D. Psychol. Rep. 16, 499-502 (1965)

7. Patrick, C. J., Bradley, M. M. \& Lang, P. J. J. Abnorm. Psychol. 102, 82-92 (1993).

8. Williamson, S. E., Harpur, T. J. \& Hare, R. D. Psychophysiology 28, 260-273 (1991).

9. Anderson, S. D., Bechara, A., Damasio, H., Tranel, D. \& Damasio, A. R. Nature Neurosci. 2, 1032-1037 (1999).

10. Blair, R. J. R., Morris, J. S., Frith, C. D., Perrett, D. I. \& Dolan, R. J. Brain 122, 883-893 (1999).

11. Raine, A. et al. Behav. Sci. Law 16, 319-332 (1998).

12. Raine, A., Lencz, T., Bihrle, S., LaCasse, L. \& Colletti, P. Arch. Gen. Psychiat. 57, 119-127 (2000).

13. Laasko, M. P. et al. Behav. Brain Res. 118, 187-193 (2001).

14. Schneider, F. et al. Neuropsychobiology 42, 192-201 (2000).

15. Seto, M. E. \& Barbaree, H. E. J. Interpers. Violence 14, 1235-1248 (1999).

NATURE|VOL 410|15 MARCH 2001 |www.nature.com 